\title{
MicroRNA-125a-5p controls the proliferation, apoptosis, migration and PTEN/MEK1/2/ERK1/2 signaling pathway in MCF-7 breast cancer cells
}

\author{
ZHONGZENG LIANG $^{1 *}$, QUNWEN PAN ${ }^{2 *}$, ZHI ZHANG $^{1}$, CHAOSHENG HUANG $^{1}$, \\ ZEMING YAN $^{1}$, YUANQI ZHANG ${ }^{1}$ and JIANWEN LI ${ }^{1}$ \\ ${ }^{1}$ Department of Vascular Thyroid Breast Surgery; ${ }^{2}$ Guangdong Key Laboratory of Age-Related Cardiac and Cerebral Diseases, \\ Institute of Neurology, The Affiliated Hospital of Guangdong Medical University, Zhanjiang, Guangdong 524001, P.R. China
}

Received May 30, 2019; Accepted September 4, 2019

DOI: $10.3892 / \mathrm{mmr} .2019 .10704$

\begin{abstract}
MicroRNA (miR)-125a-5p has shown the potential for suppressing tumorigenesis and development; however, the effects of miR-125a-5p on breast cancer cells remains unknown. The aim of this study was to evaluate the effects and underlying mechanisms of miR-125a-5p in MCF-7 breast cancer cells. MCF-7 cells were transfected with miR-125a-5p mimic or miR-125a-5p small interfering RNA to produce miR-125a-5p overexpressing/knockdown cells. Cell proliferation was assessed by an MTT assay, and cell migration ability was determined by an in vitro scratch assay. Hoechst 33258 staining and flow cytometry were performed to assess the effects of miR-125a-5p on MCF-7 apoptosis. Western blotting and reverse transcription-quantitative polymerase chain reaction were used for measuring phosphatase and tensin homolog (PTEN), phosphorylated (p)-mitogen-activated protein kinase kinase (MEK1/2)/MEK1/2, p-ERK1/2/ERK1/2, B-cell lymphoma-2 (Bcl-2), cleaved caspase-3, and miR-125a-5p expression. miR-125a-5p overexpression inhibited the proliferation and migration, but promoted the apoptosis of MCF-7 cells. These effects were associated with increases in PTEN and cleaved caspase-3 expression, and decreases in p-MEK1/2/MEK1/2, p-ERK1/2/ERK1/2, and Bcl-2. Silencing of miR-125a-5p exhibited opposing effects on MCF-7 cells. These observations suggested that miR-125a-5p participates in the regulation of multiple functions of $\mathrm{MCF}-7$ cells by promoting the expression of PTEN tumor suppressor
\end{abstract}

Correspondence to: Professor Jianwen Li or Dr Yuanqi Zhang, Department of Vascular Thyroid Breast Surgery, The Affiliated Hospital of Guangdong Medical University, 53 Renming Road, Zhanjiang, Guangdong 524001, P.R. China

E-mail: gdyfywjk@163.com

E-mail: 31428319@qq.com

*Contributed equally

Key words: microRNA-125a-5p, MCF-7, cell function, phosphatase and tensin homolog genes, activating MEK1/2/ERK1/2 signaling, and regulating caspase-3/Bcl-2 signaling. Thus, it may be a suitable target for breast cancer gene therapy.

\section{Introduction}

Breast cancer is one of the most common malignant tumors in females. It has the highest incidence among this population, and the age of onset is decreasing. The lifetime risk of having breast cancer is $10 \%$ in women (1). Approximately 500,000 people succumb to mortality each year from breast cancer, and the mortality rate increases by $2-3 \%$ annually (2). Early diagnosis and treatment have been particularly important in breast cancer as the options for primary prevention are limited. Identifying and studying the genes responsible for the growth and malignancy of breast cancer is critical for disease therapy.

MicroRNAs (miRs) bind to target genes involved in such pathologic processes as cell proliferation, differentiation and apoptosis, and affect their expression in the tissues and cells (3). miR-125a-5p has been reported to be abnormally expressed in prostate carcinoma (4). Various studies have shown miR-125a-5p to be closely related to tumor cell growth, differentiation and metastasis (5-7). Nevertheless, its effects on the proliferation, migration, and apoptosis of breast cancer cells and the underlying mechanisms remain unknown.

Phosphatase and tensin homolog (PTEN) is a well-characterized tumor suppressor, and it plays a key role in cell proliferation, migration and cell renewal by regulating the mitogen-activated protein kinase kinase (MEK)1/2/ERK1/2 pathway (8). The MEK1/2/ERK1/2 signal pathway and caspase- 3 activation have been shown to be involved in breast cancer cell proliferation, migration and apoptosis processes (9). Studies revealed that $\mathrm{miR}-125 \mathrm{a}-5 \mathrm{p}$ could regulate the MEK1/2/ERK1/2 signaling pathway in multiple cell types $(10,11)$. However, whether these proteins and pathways are involved in the mechanisms underlying miR-125a-5p regulation in breast cancer cells are unknown.

Thus, we aimed to evaluate the effects of miR-125a-5p on the biological behaviors of MCF-7 breast cancer cells and to investigate the underlying regulatory mechanisms. 


\section{Materials and methods}

Cell culture and grouping. Human MCF-7 breast cancer cells were purchased from Shanghai BioLeaf Biotech. The MCF-7 breast cancer cell line was cultured in RPMI-1640 medium containing $10 \%$ fetal bovine serum (Hyclone; GE Healthcare Life Sciences), $100 \mathrm{U} / \mathrm{ml}$ penicillin, and $100 \mu \mathrm{g} / \mathrm{ml}$ streptomycin in an incubator with $5 \% \mathrm{CO}_{2}$ and $95 \%$ humidity at $37^{\circ} \mathrm{C}$. Trypsin $(0.25 \%)$ was used to digest the cells when $80 \%$ of the cells adhered to the culture dish and for the subculture, which was performed every 2-3 days.

Lentiviral-mediated transfection to establish stable MCF-7 cell lines with miR-125a-5p overexpression or reduced miR-125a-5p expression. MCF-7 cells were infected with green fluorescent protein (GFP)-expressing lentivirus $\left(1 \times 10^{7}\right.$ multiplicity of infection) that also contained miR-125a-5p overexpression vector (LV-miR-125a-5p), miR-125a-5p silencing small interfering (si)RNA (siRNA-LV-miR-125a-5p), and a scrambled sequence (LV-NC). The medium was replaced $24 \mathrm{~h}$ after transfection, and the GFP-labeled cells were counted $72 \mathrm{~h}$ after transfection. The positive cells were screened with puromycin (final concentration of $1 \mathrm{mg} / \mathrm{l}$ ) to eventually produce MCF-7 cells with miR-125a-5p overexpression (MCF-7 ${ }^{\text {miR-125a-5p }}$ cells), MCF-7 cells with miR-125a-5p knockdown (MCF-7 ${ }^{\text {SimiR-125a-5p }}$ cells), and stable LV-scramble infected MCF-7 cells $\left(\mathrm{MCF}-7^{\mathrm{NC}}\right)$, which served as the control.

Detection of miR-125a-5p expression in MCF-7 cells. The MCF-7 ${ }^{\text {miR-125a-5p }}, \mathrm{MCF}^{-7^{\text {SimiR-125a-5p }}}$, and MCF-7 ${ }^{\mathrm{NC}}$ cells were seeded in 6-well plates. Once the MCF-7 $7^{\text {miR-125a-5p }}$, MCF-7 ${ }^{\text {SimiR-125a-5p }}$ and MCF-7 ${ }^{\text {NC }}$ cells reached $90 \%$ confluence, total RNAs of the harvested cells were extracted using TRIzol ${ }^{\circledR}$ reagent (Thermo Fisher Scientific, Inc.) a hairpin-it ${ }^{\mathrm{TM}}$ miRs reverse transcription-quantitative PCR (RT-qPCR) kit was then used to synthesize miR-125a-5p cDNA. The RT primer sequences were human miR-125a-5p-RT (5'-GTCGTATCC AGTGCAGGGTCCGAGGTGCACTGGATACGACCTGCA G-3'); U6-RT (5'-GTCGTATCCAGTGCAGGGTCCGAG GTATTCGCACTGGATACGACAAAATATGGAAC-3'), and the reverse transcription conditions were $25^{\circ} \mathrm{C}$ for $30 \mathrm{~min}, 42^{\circ} \mathrm{C}$ for $30 \mathrm{~min}$, and subsequently $85^{\circ} \mathrm{C}$ for $5 \mathrm{~min}$. The products of RT were used as templates for PCR. The primer sequences of qPCR were 5'-ACACTCCAGCTGGGTCCCTGAGAC CCTTAA-3' (miR-125a-5p forward primer), 5'-CTCAACTGG TGTGGAGT-3' (miR-125a-5p reverse primer), 5'-CTCGCT TCGGCAGCACA-3' (internal reference gene U6 forward primer), and 5'-AACGCTTCACGAATTTGCGT-3' (internal reference gene U6 reverse primer). The PCR conditions were $95^{\circ} \mathrm{C}$ denaturation for $3 \mathrm{~min}, 40$ cycles of $95^{\circ} \mathrm{C}$ denaturation for $12 \mathrm{sec}$ and $60^{\circ} \mathrm{C}$ annealing and elongation for $40 \mathrm{sec}$. The RT-qPCR procedures were performed in strict accordance with the manufacturer's instructions. Six replicate wells were performed in each group, and each experiment was performed six times. The relative expression levels of target genes were calculated using the $2^{-\Delta \Delta \mathrm{Cq}}$ method (12).

Assessment of MCF-7 cell proliferation. The harvested MCF-7 ${ }^{\text {miR-125a-5p }}$, MCF-7 ${ }^{\text {SimiR-125a-5p }}$ and MCF-7 ${ }^{\text {NC }}$ cells were independently inoculated in six wells in 96-well plates (each well contained $100 \mu \mathrm{l}$ complete cell culture medium with $2 \times 10^{3}$ cells and incubated at $37^{\circ} \mathrm{C}$ for 5 days. Cells were incubated in RPMI-164 + 10\% FBS (HyClone; GE Healthcare Life Sciences). The viability of cells in different groups was measured daily via an MTT assay for 5 days. For the MTT assay, $20 \mu$ l MTT solution was added to each well of cells for incubation at $37^{\circ} \mathrm{C}$ for $4 \mathrm{~h}$, followed by removal of the solution and addition of $150 \mu 1$ dimethyl sulfoxide, followed by incubation at $37^{\circ} \mathrm{C}$ for $20 \mathrm{~min}$; the absorbance was then measured at $490 \mathrm{~nm}$ using a microplate reader. This experiment was performed six times.

In vitro scratch assay to detect MCF-7 cell migration. The harvested MCF-7 ${ }^{\text {miR-125a-5p }}$, MCF-7 $7^{\text {SimiR-125a-5p }}$ and MCF-7 ${ }^{\text {NC }}$ cells were independently inoculated and incubated in six-well plates (each well contained $2 \mathrm{ml}$ complete cell culture medium with $5 \times 10^{4}$ cells). Each group of cells was transferred into serum-free medium once they reached $90 \%$ confluence. Then, a $200-\mu 1$ pipette tip was used to scratch a straight line in the middle of the well. The scratch width in each well was measured under an inverted microscope and the measurement points were recorded. The scratch width at the same position was measured again after incubated at $37^{\circ} \mathrm{C}$ for $16 \mathrm{~h}$. The difference between the two measurements in each well was expressed in terms of cell migration distance after $16 \mathrm{~h}$. This experiment was performed six times. Quantitative analysis of migration was calculated using the following equation: (Cell-free area at $0 \mathrm{~h}$-cell-free area at $16 \mathrm{~h}$ )/cell area at $0 \mathrm{~h} \times 100 \%$.

MCF-7 apoptosis analysis. Cell apoptosis was analyzed by Hoechst 33258 staining and an Annexin V-phycoerythrin (PE)/ 7-amino-actinomycin (7-AAD) apoptosis detection kit (BD Biosciences). The harvested MCF-7 $7^{\text {miR-125a-5p }}$, MCF- $7^{\text {SimiR-125a-5p }}$ and MCF-7 $7^{\mathrm{NC}}$ cells were independently inoculated and incubated in six-well plates (each well contained $2 \mathrm{ml}$ complete cell culture medium with $5 \times 10^{4}$ cells). Once the cells reached $90 \%$ confluence, the cells were transferred to serum-free medium for $24 \mathrm{~h}$ incubation at $37^{\circ} \mathrm{C}$ to stimulate apoptosis, which was assessed using an apoptotic cell Hoechst 33258 dye kit according to the manufacturer's protocol (Beyotime Institute of Biotechnology) and observed under a fluorescence microscope (Leica Microsystems GmbH; magnification, x400). The apoptotic cells per well were counted in five different fields of vision. The percentage of apoptotic cells per field of vision divided by the total number of cells per field of vision was obtained as the apoptotic rate.

For Annexin V-PE/7-AAD apoptosis detection, MCF-7 cells after different treatments were collected by using $0.25 \%$ trypsin and centrifuged at $200 \mathrm{xg}$ at room temperature for 3 min. Cells were then washed with PBS and resuspended in $100 \mu \mathrm{l} 1 \mathrm{X}$ annexin-binding buffer, which was included in the kit. Subsequently, $5 \mu 1$ PE-conjugated Annexin V and $5 \mu \mathrm{l}$ 7-AAD were added to the cell suspension, and incubated at room temperature for $15 \mathrm{~min}$. The rate of apoptosis in MCF-7 cells was detected by flow cytometry. The cells stained only with Annexin V were considered as MCF-7 cells in early apoptosis, and those stained for both Annexin V and 7-AAD were considered as late apoptotic cells. In this study, we defined the apoptotic cells as both early and late apoptotic cells. 
A
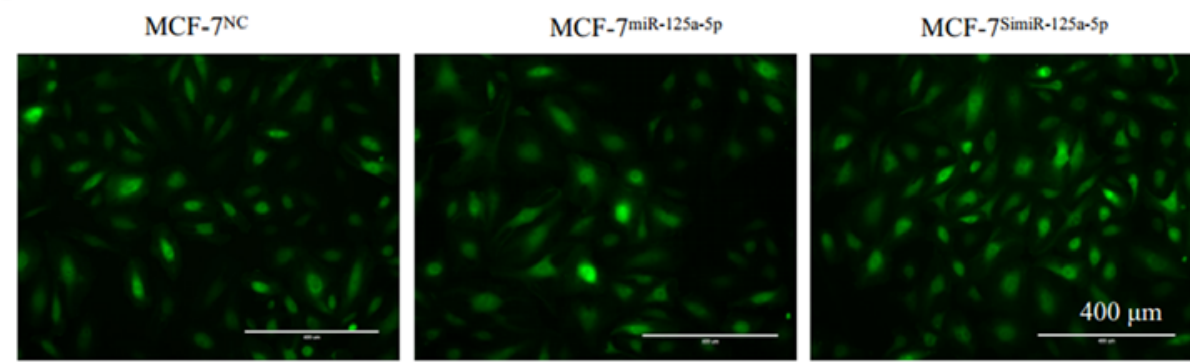

B

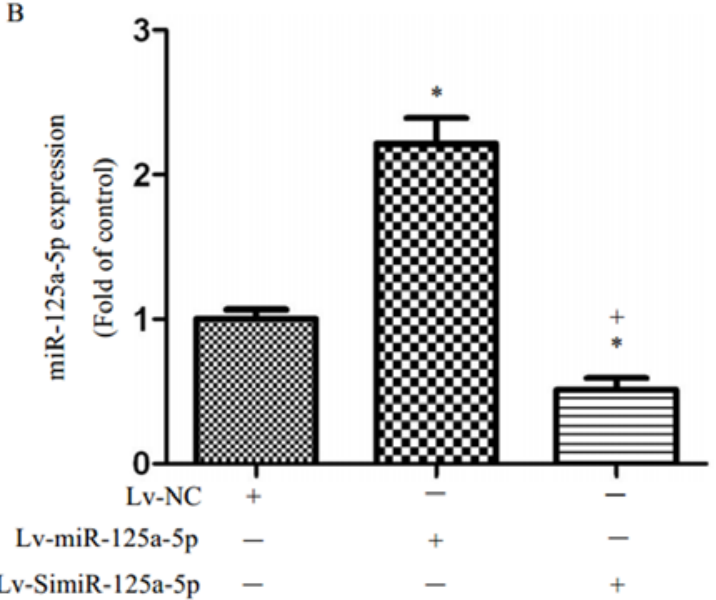

Figure 1. Overexpression and knockdown of miR-125a-5p in MCF-7 cells. (A) miR-125a-5p overexpression, silencing and control cells were observed by fluorescence microscopy. Scale bar $=400 \mu \mathrm{m}$. (B) Reverse transcription-quantitative polymerase chain reaction demonstrated the levels of miR-125a-5p in MCF-7 cells. ${ }^{*} \mathrm{P}<0.05$, vs. MCF-7 ${ }^{\mathrm{NC}}$; ${ }^{+} \mathrm{P}<0.05$, vs. MCF-7 $7^{\mathrm{miR}-125 a-5 p}$; $=6 /$ group. Lv, lentiviral; miR, microRNA; NC, negative control.

Western blotting analysis of protein expression

Protein extraction. After collecting the MCF-7 cells by centrifugation $\left(200 \times \mathrm{g}\right.$ and $4^{\circ} \mathrm{C}$ for $3 \mathrm{~min}$ ), the MCF-7 cells were lysed with RIPA buffer (Applygen Technologies, Inc.) containing protease inhibitor and subsequently centrifuged at $13,000 \times \mathrm{g}$ and $4^{\circ} \mathrm{C}$ for $10 \mathrm{~min}$ to collect the supernatant (total protein) for later use.

Western blotting. The extracted proteins were separated using 12\% SDS-PAGE and subsequently transferred to polyvinylidene difluoride (PVDF) membranes. The membranes were blocked at room temperature with Tris-buffered saline (TBS) containing 5\% fat-free dry milk (i.e., $50 \mathrm{mmol} / \mathrm{l}$ Tris, $150 \mathrm{mmol} / \mathrm{l} \mathrm{NaCl}$, pH 7.6, and 5\% fat-free dry milk) for $1 \mathrm{~h}$. After a few washes in TBS containing $0.5 \%$ Tween-20 (TBST), the protein blots were incubated with $\beta$-actin (1:1,000; cat. no. E02102001; EarthOx), PTEN (1:1,000; cat. no. 9188S; Cell Signaling Technology, Inc.), MEK1/2 (1:500; cat. no. 4694S; Cell Signaling Technology, Inc.), ERK1/2 (1:1,000; cat. no. 4695S; Cell Signaling Technology, Inc.), B-cell lymphoma-2 (Bcl-2, 1:500, cat. no. 3498S; Cell Signaling Technology, Inc.), and caspase-3 (1:400; cat. no. 9664S; Cell Signaling Technology, Inc.) primary antibodies at $4^{\circ} \mathrm{C}$ overnight. After a few washes in TBST, the protein blots were incubated with 1:50,000 horseradish peroxidase (HRP)-conjugated goat-anti-mouse secondary antibodies (cat. no. 7076S; Cell Signaling Technology, Inc.) or HRP-conjugated goat-anti-rabbit secondary antibodies (cat. no. 7074S; Cell Signaling Technology, Inc.) at room temperature for $1 \mathrm{~h}$. After three washes in TBST, the protein

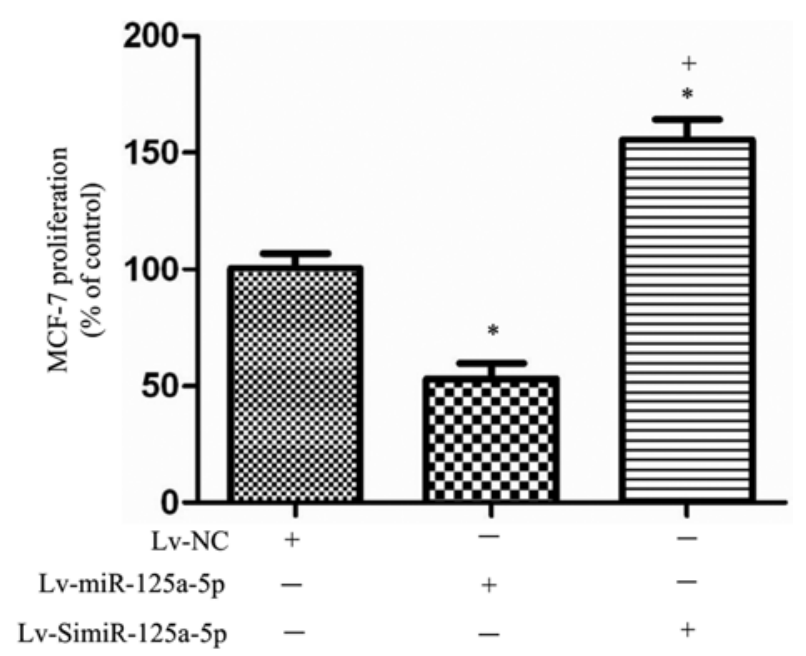

Figure 2. Effects of miR-125a-5p overexpression and silencing on MCF-7 cell proliferation. Proliferation ability of MCF-7 cells between the miR-125a-5p overexpression, silencing and control groups. ${ }^{*} \mathrm{P}<0.05$, vs. $\mathrm{MCF}-7^{\mathrm{NC}} ;{ }^{+} \mathrm{P}<0.05$, vs. MCF-7 ${ }^{\text {miR-125a-5p; }}$ n=6/group. Lv, lentiviral; miR, microRNA; NC, negative control.

blots were developed in enhanced chemiluminescence (Amersham) substrate, and then results were analyzed under Quantity one 4.6 software (Bio-Rad Laboratories, Inc.). $\beta$-actin was used as an internal reference protein. Relative protein expression was measured based on the ratio of the target protein absorbance to the $\beta$-actin protein absorbance. This experiment was performed six times. 
A

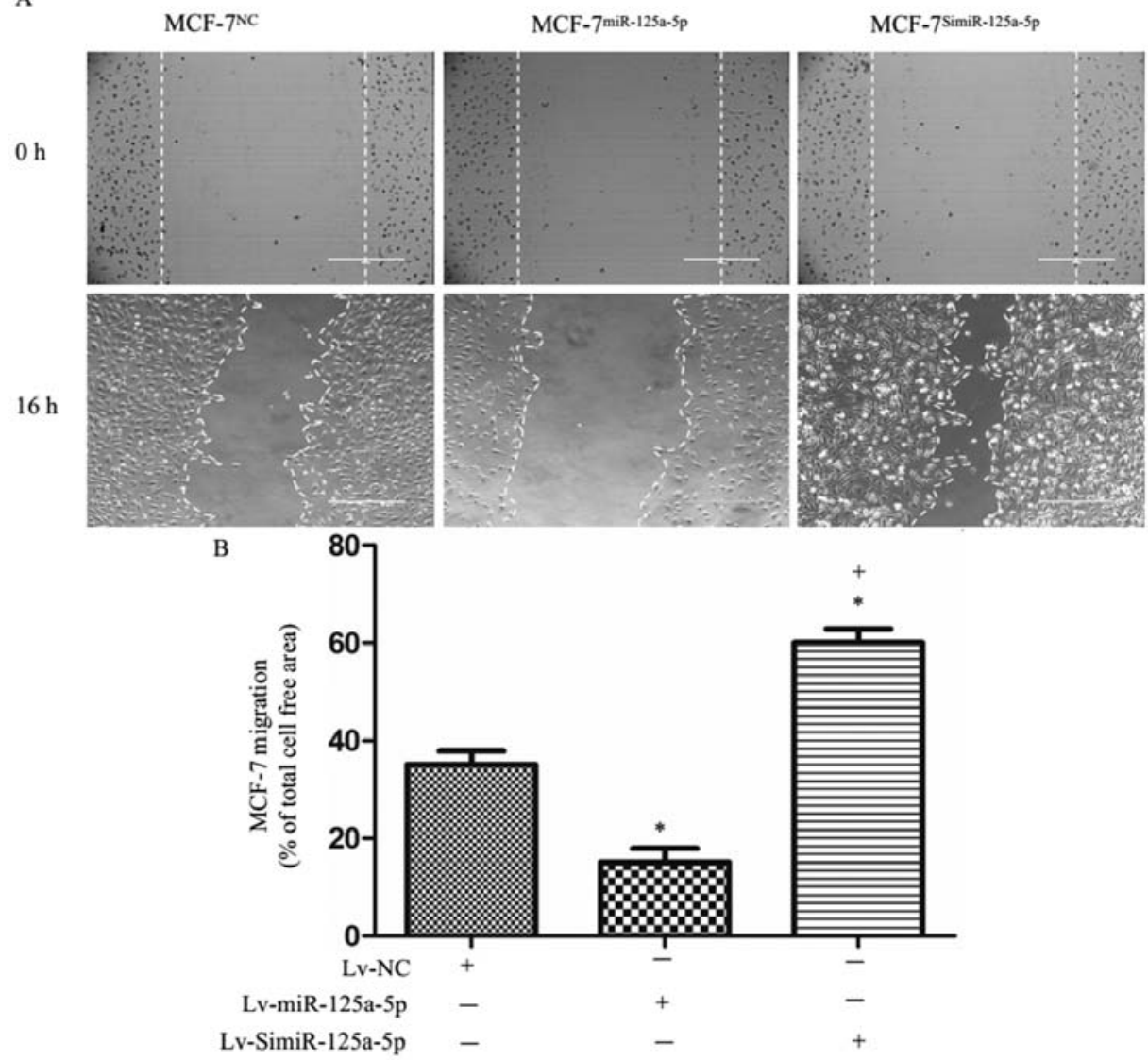

Figure 3. Effects of miR-125a-5p overexpression and silencing on the migration of MCF-7 cells. (A) Migration ability of MCF-7 cells in the miR-125a-5p overexpression, silencing and control groups. Scale bar $=400 \mu \mathrm{m}$. (B) Summarized data of the migration of MCF-7. ${ }^{*} \mathrm{P}<0.05$, vs. MCF-7 ${ }^{\mathrm{NC}}$; ${ }^{+} \mathrm{P}<0.05$, vs. MCF-7 $7^{\text {miR-125a-5p; }}$ n=6/group. Lv, lentiviral; miR, microRNA; NC, negative control.

Statistical analysis. Data were presented as the mean \pm standard deviation. Statistical analyses were performed using a t-test, one-way ANOVA followed by a least significant distance post-hoc test. GraphPad Prism 5 software (GraphPad Software, Inc.) was used for analyzing the data. $\mathrm{P}<0.05$ was considered to indicate a statistically significant difference.

\section{Results}

Overexpression and knockdown of miR-125a-5p in MCF-7 cells. MCF-7 cells were labeled with green fluorescence after transfection with LV-scramble, siRNA-LV-miR-125a-5p, or LV-miR-125a-5p and selection of stable clones (Fig. 1A). The results of RT-qPCR showed that miR-125a-5p expression in the MCF-7 ${ }^{\mathrm{miR}-125 \mathrm{a}-5 \mathrm{p}}$ cells was significantly higher than in the MCF- ${ }^{\mathrm{NC}}$ cells $(\mathrm{P}<0.05$; Fig. 1B); in addition, there miR-125a-5p expression was significantly reduced in the MCF-7 ${ }^{\text {SimiR-125a-5p }}$ cells than in $\mathrm{MCF}-7^{\mathrm{NC}}$ cells $(\mathrm{P}<0.05$; Fig. 1B).

miR-125a-5p is involved in MCF-7 cell proliferation and migration. The results of the MTT assay showed the viability of MCF-7 cells in different groups. Starting from the 3rd day of experiment, the proliferation rate of the MCF- $7^{\text {miR-125a-5p }}$ cells was significantly lower than that of $\mathrm{MCF}-7^{\mathrm{NC}}$ cells $(\mathrm{P}<0.05$; Fig. 2), while the proliferation rate of the MCF-7 $7^{\text {simiR-125a-5p }}$ cells was significantly higher than that of $\mathrm{MCF}-7^{\mathrm{NC}}$ cells $(\mathrm{P}<0.05$; Fig. 2). This suggested that high miR-125a-5p expression inhibited the proliferation of MCF-7 cells, and low miR-125a-5p expression promoted this ability within MCF-7 cells.

The results of in vitro scratch assay revealed that migration ability of MCF-7 ${ }^{\text {miR-125a-5p }}$ cells was significantly lower than the MCF-7 ${ }^{\mathrm{NC}}$ cells $(\mathrm{P}<0.05$; Fig. $3 \mathrm{~A}$ and $\mathrm{B})$, while that of the MCF-7 $7^{\text {SimiR-125a-5p }}$ cells was significantly higher than the MCF- $7^{\mathrm{NC}}$ cells $(\mathrm{P}<0.05$; Fig. $3 \mathrm{~A}$ and $\mathrm{B})$. These results indicated that high miR-125a-5p expression inhibited the migration of MCF-7 cells. Conversely, low miR-125a-5p expression in MCF-7 cells resulted in enhanced migration of the cells.

miR-125a-5p increases PTEN/ MEK1/2/ ERK1/2 pathway protein expression in $M C F-7$ cells. PTEN protein expression in MCF-7 ${ }^{\text {miR-125a-5p }}$ cells was significantly higher than in $\mathrm{MCF}-7^{\mathrm{NC}}$ cells $(\mathrm{P}<0.05$; Fig. $4 \mathrm{~A}$ and $\mathrm{B})$. In contrast, significantly reduced $\mathrm{PTEN}$ protein expression was exhibited by MCF-7 $7^{\text {SimiR-125a-5p }}$ cells compared with $\mathrm{MCF}-7^{\mathrm{NC}}$ and MCF-7 ${ }^{\text {miR-125a-5p }}$ cells $(\mathrm{P}<0.05$; Fig. $4 \mathrm{~A}$ and $\mathrm{B})$. In addition, we found that overexpression of miR-125a-5p significantly decreased the phosphorylation levels of MEK1/2 and ERK1/2 in MCF-7 cells compared with the MCF-7 ${ }^{\mathrm{NC}}$ group $(\mathrm{P}<0.05$; Fig. 4A,C and D). Additionally, silencing miR-125a-5p significantly increased the phosphorylation levels of MEK1/2 and ERK1/2 in MCF-7 cells compared with the MCF-7 $7^{\text {miR-125a-5p }}$ group $(\mathrm{P}<0.05$, Fig. 4A,C and D). These data suggested that the PTEN/MEK1/2/ERK1/2 signaling pathway may have 
A
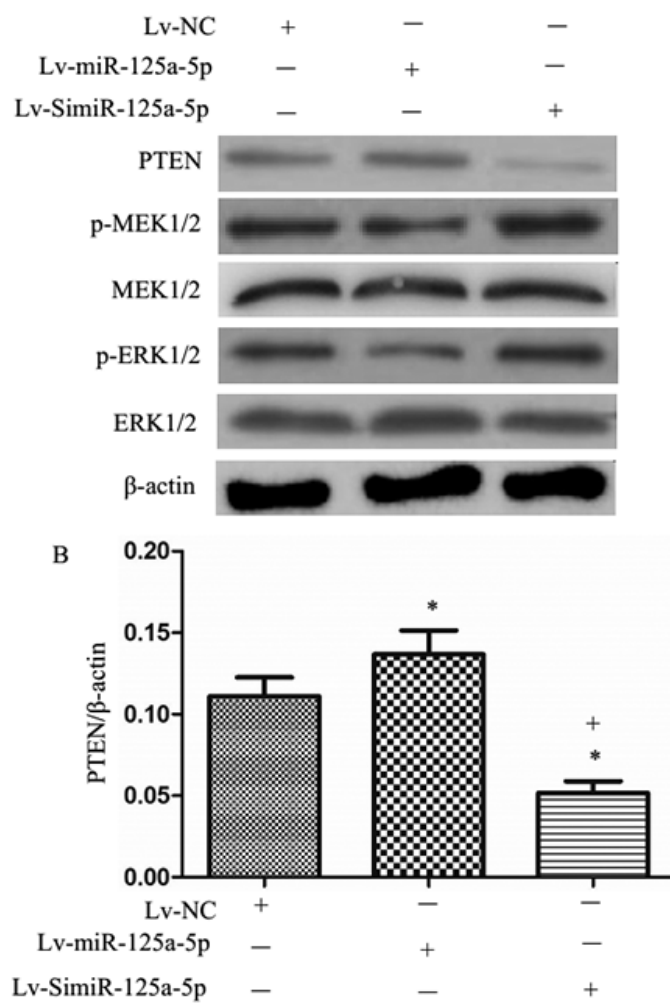

C

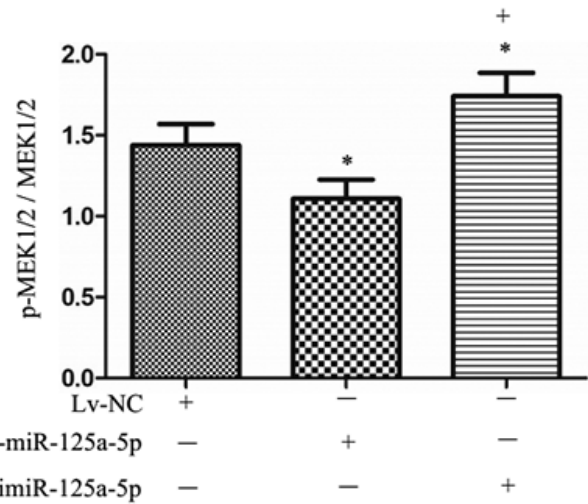

D

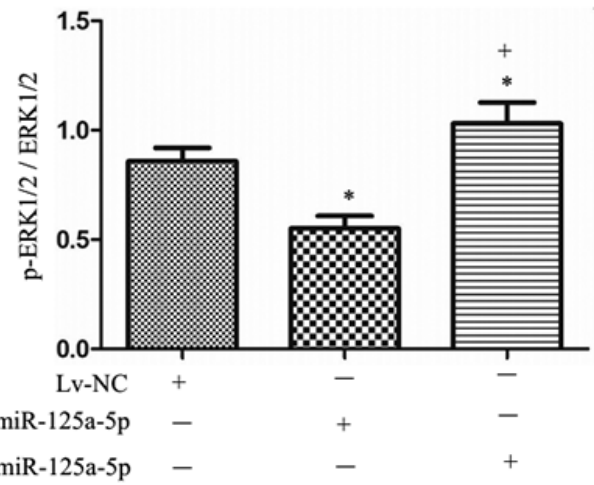

Figure 4.Effects of miR-125a-5p on PTEN,p-MEK1/2/MEK1/2, and p-ERK1/2/ERK1/2 expression in MCF-7 cells. (A) Expression of PTEN,p-MEK1/2/MEK1/2, and p-ERK1/2/ERK1/2 in MCF-7 cells. (B) Summarized data of the PTEN expression. (C) Summarized data of the p-MEK1/2 /MEK1/2 level. (D) Summarized data of the p-ERK1/2/ERK1/2 level. ${ }^{*} \mathrm{P}<0.05$, vs. MCF-7 ${ }^{\mathrm{NC}}$; ${ }^{+} \mathrm{P}<0.05$, vs. MCF-7 ${ }^{\text {miR-125a-5p; }}$ n=6/group. ERK, extracellular signal-regulated kinase; Lv, lentiviral; MEK, mitogen-activated protein kinase kinase; miR, microRNA; NC, negative control; p, phosphorylated; PTEN, phosphatase and tensin homolog.

contributed to the effects of miR-125a-5p on inhibiting MCF-7 cell proliferation and migration.

miR-125a-5p pomotes the apoptosis of MCF-7 cells, which is accompanied with increased cleaved caspase-3 and decreased Bcl-2 levels. Hoechst 33258 staining and flow cytometry showed that the rate of apoptosis among MCF-7 ${ }^{\text {miR-125a-5p }}$ cells was significantly higher than that of the MCF-7 ${ }^{\mathrm{NC}}$ cells $(\mathrm{P}<0.05$; Fig. 5A-D), while the apoptotic rate of the MCF-7 ${ }^{\text {SimiR-125a-5p }}$ cells was significantly lower than that of the MCF- ${ }^{\mathrm{NC}}$ cells $(\mathrm{P}<0.05$, Fig. 5A-D). These results indicated that high levels of miR-125a-5p promoted, while low levels of miR-125a-5p reduced the apoptosis of MCF-7 cells.

In addition, via western blotting, we monitored the levels of cleaved caspase-3 and $\mathrm{Bcl}-2$, which are associated with induction of apoptosis (13). The results showed that overexpression of miR-125a-5p significantly increased cleaved caspase-3 expression, while decreased Bcl-2 expression was observed compared with the control $(\mathrm{P}<0.05$; Fig. 6A-C). Silencing miR-125a-5p in MCF-7 cells revealed significantly decreased cleaved caspase-3 protein expression and increased $\mathrm{Bcl}-2$ expression compared with the control and overexpression groups $(\mathrm{P}<0.05$; Fig. 6A-C).

\section{Discussion}

In the present study, we found that miR-125a-5p inhibited MCF-7 migration and proliferation, but promoted apoptosis.
The effects of miR-125a-5p on MCF-7 cell migration and proliferation may be associated with an increase in PTEN, and decrease in MEK1/2 and ERK1/2 protein expression, while the apoptotic effects could be associated with upregulated cleaved caspase-3 levels.

The survival time of breast cancer patients is closely related to the pathological stage of breast cancer: The earlier the pathological stage at the time of diagnosis, the higher the recovery rate (14). For this reason, and as there are currently no effective primary prevention methods, early diagnosis and treatment are particularly important in breast cancer $(2,15)$. Mammography, ultrasonography, computed tomography, magnetic resonance imaging and biopsies are commonly used for the diagnosis of breast cancer (16). However, each diagnostic method has its limitations. Breast cancer treatments mainly include surgery, chemotherapy, radiotherapy, endocrine therapy, and biological targeted therapy (14). Although these treatments prolong patient survival, and the postoperative recurrent and metastatic rates are still relatively high, it is important to study the mechanism underlying the development and progression of breast cancer. Thus, novel therapeutic targets for breast cancer could be identified.

miRs are non-coding single-stranded small RNAs. They are $\sim 18-25$ nucleotides in length with high evolutionarily conservation (17). It binds to its target mRNAs to inhibit translation and induce degradation of the mRNA, altering the levels of expression of the target protein (18). miR-125a expression is low in breast cancer tissues, and was negatively correlated with 


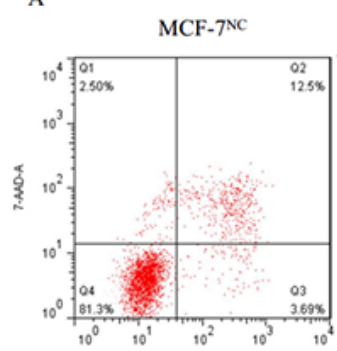

$P E-A$

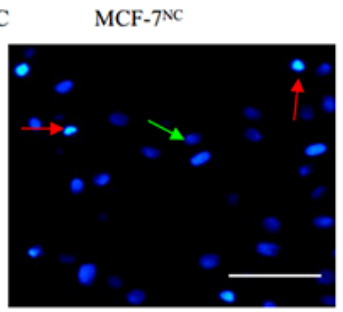

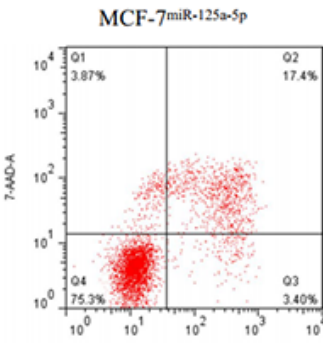

PEA

MCF-7miR-125asp

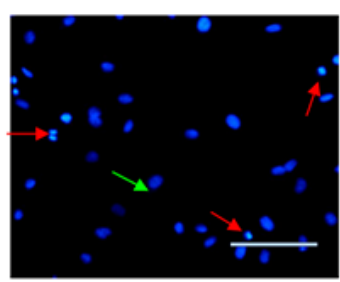

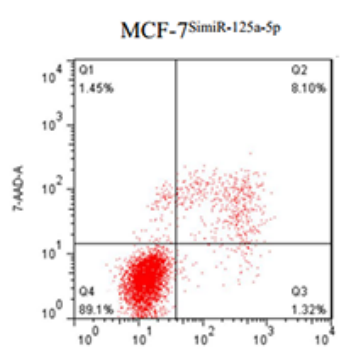

PE-A
B

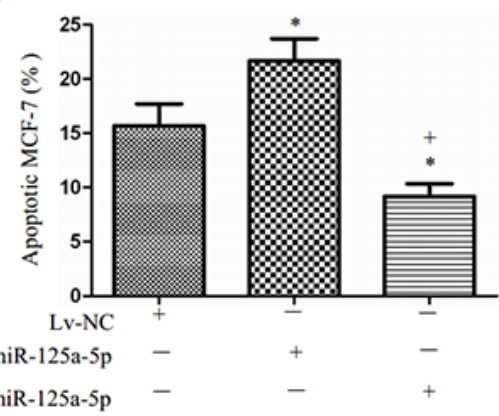

D

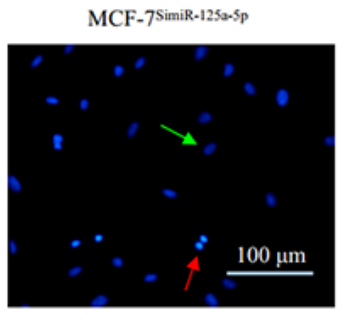

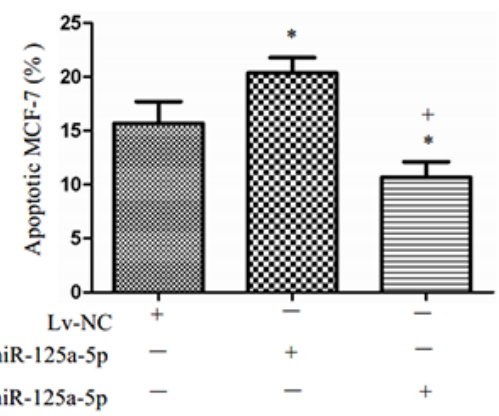

Figure 5. Effects of miR-125a-5p on serum deprivation-induced apoptosis of MCF-7 cells. (A and B) Representative images and summarized data of MCF-7 apoptosis as detected by flow cytometry. (C and D) Representative images and summarized data of MCF-7 apoptosis as detected by Hoechst 33258 staining. Scale bar $=100 \mu \mathrm{m} .{ }^{*} \mathrm{P}<0.05$, vs. MCF-7 ${ }^{\mathrm{NC}}$; ${ }^{\mathrm{P}}<0.05$, vs. MCF-7 ${ }^{\mathrm{miR}-125 \mathrm{a}-5 \mathrm{p}}$; n=6/group. 7-AAD, 7-amino-actinomycin; Lv, lentiviral; miR, microRNA; NC, negative control; PE, phycoerythrin.
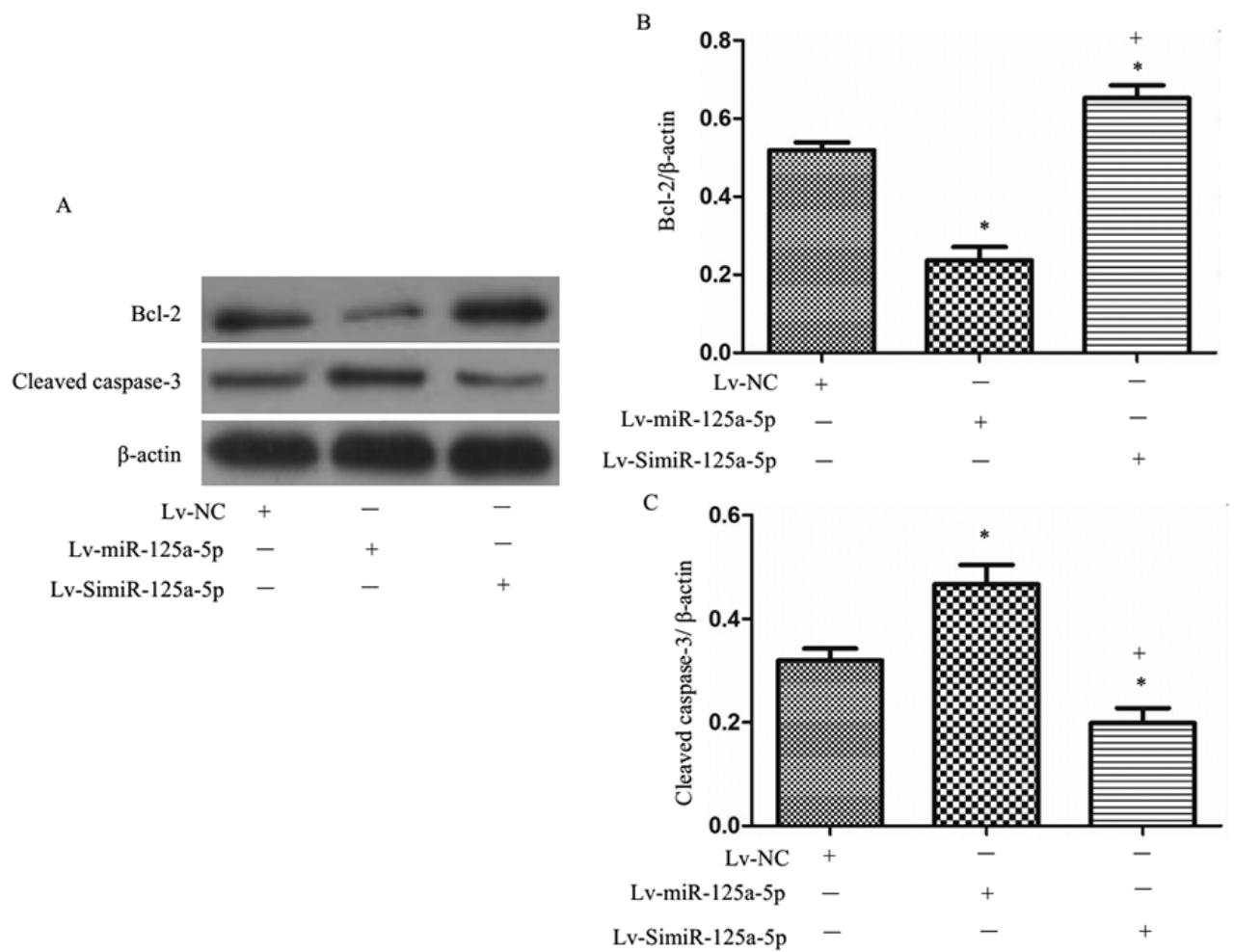

Figure 6. Effects of miR-125a-5p on cleaved caspase-3 and Bcl-2 expression in MCF-7 cells. (A) Expression of cleaved caspase-3 and Bcl-2 in MCF-7 cells. (B) Summarized data of the cleaved caspase-3 expression. (C) Summarized data of the Bcl-2 level. ${ }^{*} \mathrm{P}<0.05$, vs. MCF-7 ${ }^{\mathrm{NC}}$; ${ }^{+} \mathrm{P}<0.05$, vs. MCF-7 ${ }^{\mathrm{miR}-125 \mathrm{a}-5 \mathrm{p} \text {; }}$ $\mathrm{n}=6$ /group. Bcl-2, B-cell lymphoma-2; Lv, lentiviral; miR, microRNA; NC, negative control.

tumor size, lymph node metastasis and clinical stage of breast cancer (19). Previous studies have reported that miR-125a is closely related to tumor cell growth, differentiation, and metastasis (20,21). A study by Scott et al (20) has shown that miR-125a downregulates human epidermal growth factor receptor 2 (ERBB2) and ERBB3 protein and mRNA expression 
by targeting ERBB2 and ERBB3; furthermore, miR-125a inhibited the migration and invasion of SKBR3 breast cancer cells. To the bet of our knowledge, our study, for the first time found that miR-125a-5p inhibited the proliferation and migration, and promoted the apoptosis of MCF-7 cells. Collectively, these findings demonstrated that miR-125a-5p is a candidate target for breast cancer therapy.

The MEK1/2/ERK1/2 pathway is extensively involved in the proliferation and the migration-associated protein expression of tumor cells (22), and serves an important role in tumor development and progression. A study by Hsieh et al (19) indicated that human aldo-keto reductase family 1 member B10 promotes the invasion and migration of MCF-7 cells by activating the MEK1/2/ERK1/2 pathway. Another study reported that the activation of ERK1/2/p38 MAPK signaling is involved in the regulation of invasion and metastasis of MDA-MB-231 breast cancer cells (23). These studies suggest that abnormal activation of the MEK1/2/ERK1/2 pathway may be an important mechanism underlying the development of breast cancer. In this study, MEK1/2 /ERK1/2 signaling was inhibited in MCF-7 breast cancer cells with high miR-125a-5p expression. In contrast, we observed that knockdown of miR-125a-5p expression led to activation of MEK1/2 /ERK1/2 signaling. PTEN, located on human chromosome 10, is a tumor suppressor gene that inhibits the growth and migration of various tumors by negatively regulating the PI3K/Akt/mTOR pathway $(24,25)$. A recent study revealed that PTEN also inhibits the migration of type 2 endometrial cancer cells by negatively regulating the MEK1/2/ERK1/2 pathway (26). In this study, high levels of miR-125a-5p expression promoted PTEN expression in MCF-7 cells, while knockdown of miR-125a-5p expression significantly reduced PTEN expression in MCF-7 cells. This suggested that miR-125a-5p inhibited the protein expression of the MEK1/2/ERK1/2 pathway proteins by upregulating the expression of PTEN, playing a tumor suppressive role.

Caspase-3 is an important pro-apoptotic factor that plays an important role in the process of apoptosis. Bcl-2 is an important anti-apoptotic gene that serves a key role in the regulation of early apoptosis in cells (13). One recent study has shown that cyanidin-3-glucoside inhibits MDA-MB-231 breast cancer cells by promoting caspase-3 expression and downregulating Bcl-2 expression (27). In this study, we found that high miR-125a-5p expression promoted the apoptosis of $\mathrm{MCF}-7$ cells, while knockdown of miR-125a-5p expression significantly lowered the rate of apoptosis among MCF-7 cells. Our study into the underlying mechanism showed that high levels of miR-125a-5p expression promoted the expression of pro-apoptotic protein, caspase- 3 and inhibited the expression of anti-apoptotic protein $\mathrm{Bcl}-2$. These results indicated that miR-125a-5p might be involved in regulating apoptosis in MCF-7 breast cancer cells by regulating the caspase/Bcl-2 pathway.

In summary, the present study demonstrated a potential role of miR-125a-5p in the pathogenesis of breast cancer via control of cancer cell proliferation, apoptosis and migration. In addition, our data indicated that miR-125a-5p exerted these functions in breast cancer cells by upregulating PTEN expression and inhibiting the activity of the MEK1/2/ERK1/2 pathway. However, further in-depth and in vivo investigations into the role, and the precise mechanisms underlying
miR-125a-5p regulation in breast cancer should be conducted in the future.

\section{Acknowledgements}

Not applicable.

\section{Funding}

This work was supported by the Medical Scientific Research Foundation of Guangdong Province (grant no. A2018490) and the Science and Technology Innovation Fund of Guangdong Medical University (grant nos. M2015012 and M2016049).

\section{Availability of data and materials}

All data generated or analyzed during this study are included in this published article.

\section{Authors' contributions}

ZL, JL and QP designed the experiments. ZL, QP, ZZ, CH, ZY and YZ performed the experiments. ZL, JL, QP analyzed the data. ZL and QP interpreted the data. ZL and QP drafted the manuscript. JL and QP revised the manuscript. All authors read and approved the final version of the manuscript.

\section{Ethics approval and consent to participate}

Not applicable.

\section{Patient consent for publication}

Not applicable.

\section{Competing interests}

The authors declare that they have no competing interests.

\section{References}

1. Amin A, Shriver CD, Henry LR, Lenington S, Peoples GE and Stojadinovic A: Breast cancer screening compliance among young women in a free access healthcare system. J Surg Oncol 97: 20-24, 2008

2. Jemal A, Ward EM, Johnson CJ, Cronin KA, Ma J, Ryerson B, Mariotto A, Lake AJ, Wilson R, Sherman RL, et al: Annual report to the Nation on the status of cancer, 1975-2014, featuring survival. J Natl Cancer Inst 109: 2017.

3. Filipowicz W, Bhattacharyya SN and Sonenberg N: Mechanisms of post-transcriptional regulation by microRNAs: Are the answers in sight? Nat Rev Genet 9: 102-114, 2008.

4. Fu Y and Cao F: MicroRNA-125a-5p regulates cancer cell proliferation and migration through NAIF1 in prostate carcinoma. Onco Targets Ther 8: 3827-3835, 2015.

5. Guo X, Wu Y and Hartley RS: MicroRNA-125a represses cell growth by targeting HuR in breast cancer. RNA Biol 6: 575-583, 2009.

6. Cai M, Chen Q, Shen J, Lv C and Cai L: Epigenetic silenced miR-125a-5p could be self-activated through targeting Suv39H1 in gastric cancer. J Cell Mol Med 22: 4721-4731, 2018.

7. Huang WK, Akçakaya P, Gangaev A, Lee L, Zeljic K, Hajeri P, Berglund E, Ghaderi M, Åhlén J, Bränström R, et al: miR-125a-5p regulation increases phosphorylation of FAK that contributes to imatinib resistance in gastrointestinal stromal tumors. Exp Cell Res 371: 287-296, 2018. 
8. Zhang X, Jin T, Huang X, Liu X, Liu Z, Jia Y and Hao J: Effects of the tumor suppressor PTEN on biological behaviors of activated pancreatic stellate cells in pancreatic fibrosis. Exp Cell Res 373: 132-144, 2018.

9. Dong Q, Yang B, Han JG, Zhang MM, Liu W, Zhang X, Yu HL, Liu ZG, Zhang SH, Li T, et al: A novel hydrogen sulfide-releasing donor,HA-ADT, suppresses the growth of human breast cancer cells through inhibiting the PI3K/AKT/mTOR and Ras/Raf/MEK/ERK signaling pathways. Cancer Lett 455: 60-72, 2019.

10. Liang Y, Ye J, Jiao J, Zhang J, Lu Y, Zhang L, Wan D, Duan L, $\mathrm{Wu}$ Y and Zhang B: Down-regulation of miR-125a-5p is associated with salivary adenoid cystic carcinoma progression via targeting p38/JNK/ERK signal pathway. Am J Transl Res 9: 1101-1113, 2017.

11. Pan Q, Liao X, Liu H, Wang Y, Chen Y, Zhao B, Lazartigues E, Yang Y and Ma X: MicroRNA-125a-5p alleviates the deleterious effects of ox-LDL on multiple functions of human brain microvessel endothelial cells. Am J Physiol Cell Physiol 312: C119-C130, 2017.

12. Livak KJ and Schmittgen TD: Analysis of relative gene expression data using real-time quantitative PCR and the 2(-Delta Delta C(T)) method. Methods 25: 402-408, 2001.

13. Kluck RM, Bossy-Wetzel E, Green DR and Newmeyer DD: The release of cytochrome $\mathrm{c}$ from mitochondria: A primary site for $\mathrm{Bcl}-2$ regulation of apoptosis. Science 275: 1132-1136, 1997.

14. de la Mare JA, Contu L, Hunter MC, Moyo B, Sterrenberg JN, Dhanani KC, Mutsvunguma LZ and Edkins AL: Breast cancer: Current developments in molecular approaches to diagnosis and treatment. Recent Pat Anticancer Drug Discov 9: 153-175, 2014.

15. Jafari SH, SaadatpourZ, Salmaninejad A, MomeniF, Mokhtari M, Nahand JS, Rahmati M, Mirzaei H and Kianmehr M: Breast cancer diagnosis: Imaging techniques and biochemical markers. J Cell Physiol 233: 5200-5213, 2018.

16. M Braden A, V Stankowski R, M Engel J and A Onitilo A: Breast cancer biomarkers: Risk assessment, diagnosis, prognosis, prediction of treatment efficacy and toxicity, and recurrence. Curr Pharm Des 20: 4879-4898, 2014.

17. Hayes J,Peruzzi PP and Lawler S: MicroRNAs in cancer: Biomarkers, functions and therapy. Trends Mol Med 20: 460-469, 2014

18. Bartel DP: MicroRNAs: Target recognition and regulatory functions. Cell 136: 215-233, 2009.

19. Hsieh TH, Hsu CY, Tsai CF, Long CY, Chai CY, Hou MF, Lee JN, Wu DC, Wang SC and Tsai EM: miR-125a-5p is a prognostic biomarker that targets HDAC4 to suppress breast tumorigenesis. Oncotarget 6: 494-509, 2015
20. Scott GK, Goga A, Bhaumik D, Berger CE, Sullivan CS and Benz CC: Coordinate suppression of ERBB2 and ERBB3 by enforced expression of micro-RNA miR-125a or miR-125b. J Biol Chem 282: 1479-1486, 2007.

21. Liu X, Du L and Feng R: c-Src regulates cell cycle proteins expression through protein kinase B/glycogen synthase kinase 3 beta and extracellular signal-regulated kinases $1 / 2$ pathways in MCF-7 cells. Acta Biochim Biophys Sin (Shanghai) 45: 586-592, 2013.

22. Jafari SM, Joshaghani HR, Panjehpour M and Aghaei M: A2B adenosine receptor agonist induces cell cycle arrest and apoptosis in breast cancer stem cells via ERK1/2 phosphorylation. Cell Oncol (Dordr) 41: 61-72, 2018.

23. Düzgün ŞA, Yerlikaya A, Zeren S, Bayhan Z, Okur E and Boyacı I: Differential effects of p38 MAP kinase inhibitors SB203580 and SB202190 on growth and migration of human MDA-MB-231 cancer cell line. Cytotechnology 69: 711-724, 2017.

24. Mashayekhi S, Yousefi B, Tohidi E, Darband SG, Mirza-Aghazadeh-Attari M, Sadighparvar S, Kaviani M, Shafiei-Irannejad V, Kafil HS, Karimian A, et al: Overexpression of tensin homolog deleted on chromosome ten (PTEN) by ciglitazone sensitizes doxorubicin-resistance leukemia cancer cells to treatment. J Cell Biochem 120: 15719-15729, 2019.

25. Ocana A, Vera-Badillo F, Al-Mubarak M, Templeton AJ, Corrales-Sanchez V, Diez-Gonzalez L, Cuenca-Lopez MD, Seruga B, Pandiella A and Amir E: Activation of the $\mathrm{PI} 3 \mathrm{~K} / \mathrm{mTOR} / \mathrm{AKT}$ pathway and survival in solid tumors: Systematic review and meta-analysis. PLoS One 9: e95219, 2014

26. Xiong S, Cheng JC, Klausen C, Zhao J and Leung PC: TGF- $\beta 1$ stimulates migration of type II endometrial cancer cells by down-regulating PTEN via activation of SMAD and ERK1/2 signaling pathways. Oncotarget 7: 61262-61272, 2016.

27. Cho E, Chung EY, Jang HY, Hong OY, Chae HS, Jeong YJ, Kim SY, Kim BS, Yoo DJ, Kim JS and Park KH: Anti-cancer effect of cyanidin-3-glucoside from mulberry via caspase-3 cleavage and DNA fragmentation in vitro and in vivo. Anticancer Agents Med Chem 17: 1519-1525, 2017.

This work is licensed under a Creative Commons Attribution-NonCommercial-NoDerivatives 4.0 International (CC BY-NC-ND 4.0) License. 